\title{
Inulin-type fructans trigger changes in iron concentration and activity of bone metabolism biomarkers in blood plasma of growing pigs
}

\author{
A. Lepczyński ${ }^{1,3}$, A. Herosimczyk ${ }^{1}$, M. Barszcz² ${ }^{2}$ M. Ożgo ${ }^{1}$, M. Taciak $^{2}$ and J. Skomiał ${ }^{2}$ \\ ${ }^{1}$ West Pomeranian University of Technology Szczecin, Department of Physiology, Cytobiology and Proteomics \\ Doktora Judyma 6, 71-466 Szczecin, Poland \\ ${ }^{2}$ The Kielanowski Institute of Animal Physiology and Nutrition, Polish Academy of Sciences \\ Instytucka 3, 05-110 Jabłonna, Poland
}

KEY WORDS: chicory, dietary fibre, biochemical indices, minerals liver, bone metabolism, piglets

\begin{abstract}
The aim of the study was to estimate the influence of dietary supplementation with dried chicory root and native chicory inulin on biochemical profile of blood plasma. In total 24 male piglets were divided into 3 groups $(n=8)$ and fed unsupplemented cereal-based diet (C diet), diet with $2 \%$ of native chicory inulin (T1 diet) or with $4 \%$ of dried chicory root (T2 diet). After 40 days of feeding pigs were sacrificed and blood plasma samples were taken for biochemical analysis. Plasma albumin concentration, as well as alkaline phosphatase and alanine aminotransferase activity, were significantly higher in the group of animals fed T2 diet. Plasma $\gamma$-glutamyltransferase activity was significantly lower in the pigs fed T2 diet when compared to animals fed C and T1 diets. Significant increase in plasma iron concentration in animals fed T2 diet and slightly increased calcium level in both treatment groups were observed. It can be concluded that dietary fructans and dried chicory root do not affect liver functioning. Feeding growing pigs diet supplemented with dried chicory root significantly improves plasma iron concentration and may increase blood plasma calcium concentration what, in turn, may enhance bone mineralization and growth in young animals.
\end{abstract}

${ }^{3}$ Corresponding author:

e-mail: adam.lepczynski@zut.edu.pl health'. Inulin type-fructans (ITF), i.e. inulin and fructooligosaccharides fulfil these criteria (Gibson and Roberfoid, 1995). Ingestion of ITF significantly changes the gut microbiota composition, favouring the growth of bifidobacteria and/or lactobacilli (Seifert and Watzl, 2007). These beneficial bacterial groups affect metabolism of the host through e.g., increased short-chain fatty acid (SCFA) formation (Seifert and Waltz, 2007).

SCFAs directly contribute to the enhancement of intestinal absorption of $\mathrm{Ca}, \mathrm{Mg}$ and $\mathrm{Fe}$ (Yasuda et al., 2006, 2009; Scholz-Ahrens and Schrezenmeir, 2007). 
Additionally, butyrate is largely metabolized by the colonic epithelium. The remaining pool of SCFAs is absorbed via colonic mucosa and affects peripheral tissue metabolism. ITF indirectly exert multiple systemic effects, including plasma and liver lipid regulation, improvement of immunological status (Lepczynski et al., 2015) and bone mass enhancement (Abrams et al., 2005). The results of our recent study showed significant changes in expression of hepatic proteins involved in energetic metabolism and oxidative stress prevention in young pigs in response to diets supplemented with either native inulin or dried chicory root (Lepczyński et al., 2016). Moreover, Nasiri et al. (2014) demonstrated detoxifying properties of chicory inulin. So, the aim of the present study was to estimate the influence of dietary supplementation with dietary chicory root and native chicory inulin on biochemical profile of blood plasma that can reflect liver and mineral status in growing pigs.

\section{Material and methods}

\section{Animals, diets and housing}

The experimental protocols were approved by the Local Commission of Ethics for the Care and Use of Laboratory Animals (No. 13/2012). The experiment was carried on 24 castrated male piglets $(\mathrm{PIC} \times$ Penarlan P76) divided into 3 groups $(\mathrm{n}=8)$. Animals were fed from the day 10 of life unsupplemented cereal-based diet (control, $\mathrm{C}$ diet), diet with $2 \%$ of native chicory inulin ( $\mathrm{T} 1 \mathrm{diet}$ ), with an average degree of polymerization (DP) $\geq 10$, or with $4 \%$ of dried chicory root (T2 diet) (Table 1$)$. The ITF level was similar (approximately $2 \%$ ) in both $\mathrm{T} 1$ and $\mathrm{T} 2$ diets.

Until weaning at 28 day of life, the piglets were kept with their sows in farrowing pens on a commercial farm (4 litters per group). Then, 2 piglets from each litter were chosen and transported to the experimental facility, where they were divided according to dietary treatment and placed into pens of 4 piglets each ( 2 pens per group). Housing temperature was maintained at $25^{\circ} \mathrm{C}$ and dark : light cycle was set at $12 \mathrm{~h}$ light : $12 \mathrm{~h}$ dark. The animals had free access to feed and water throughout the experiment. After 40 days of feeding on experimental diets (50 day of life), the pigs were sacrificed by electrocution and exsanguinated. Blood samples were collected into heparinized tubes, centrifuged at $3000 \mathrm{rpm}$ for 10 min at $4{ }^{\circ} \mathrm{C}$ and plasma for biochemical analyses was stored at $-40{ }^{\circ} \mathrm{C}$ until used.

\section{Analysis of biochemical parameters of blood plasma}

The content of total protein, albumin, urea, creatinine and total bilirubin, activity of aspartate aminotransferase (AST), alanine aminotransferase (ALT), alkaline phosphatase (ALP), $\gamma$-glutamyltransferase (GGT), lactate dehydrogenase (LDH), creatine kinase (CK), amylase (AMY) and cholinesterase (CCK), total iron binding capacity (TIBC), and content of iron, calcium, phosphorus, magnesium and chloride in blood plasma were determined spectrophotometrically on a MAXMAT PL multidisciplinary diagnostic platform (Erba Diagnostics France SARL, Montpellier, France) using readyto-use reagents (ELITech Group, Puteaux, France).

Table 1. Composition of control diet (C) and diets supplemented with $2 \%$ of chicory inulin (T1) or $4 \%$ of dried chicory root (T2)

\begin{tabular}{llll}
\hline Ingredient, \% & Diet & & \\
\cline { 2 - 4 } & $\mathrm{C}$ & $\mathrm{T} 1$ & $\mathrm{~T} 2$ \\
\hline Wheat & 46.84 & 46.84 & 45.84 \\
Barley & 20 & 20 & 20 \\
Maize starch & 3.0 & 1.0 & - \\
Full-fat soyabean & 5.9 & 5.9 & 5.9 \\
Whey & 9.7 & 9.7 & 9.7 \\
Fish meal & 4.0 & 4.0 & 4.0 \\
Spray-dried blood plasma & 4.0 & 4.0 & 4.0 \\
Soyabean oil & 3.4 & 3.4 & 3.4 \\
Calcium formate & 0.3 & 0.3 & 0.3 \\
Limestone & 0.5 & 0.5 & 0.5 \\
Dicalcium phosphate & 0.6 & 0.6 & 0.6 \\
Sodium chloride & 0.07 & 0.07 & 0.07 \\
L-lysine & 0.61 & 0.61 & 0.61 \\
DL-methionine & 0.23 & 0.23 & 0.23 \\
L-threonine & 0.26 & 0.26 & 0.26 \\
L-tryptophan & 0.09 & 0.09 & 0.09 \\
Mineral-vitamin premix ${ }^{1}$ & 0.4 & 0.4 & 0.4 \\
Aroma & 0.1 & 0.1 & 0.1 \\
Inulin & - & 2.0 & - \\
Dried chicory roots & - & - & 4.0 \\
\hline
\end{tabular}

${ }^{1}$ Premix composition, per kg: IU: vit. A 600 000, vit. $D_{3} 60$ 000; mg: vit. $E 3000$, vit. $K_{3} 120$, vit. $B_{1} 120$, vit. $B_{2} 240$, vit. $B_{6} 240$, nicotinic acid 1600 , pantothenic acid 800 , folic acid 160 , biotin 10 , vit. $B_{12} 1.6$, I 40, Se 16, Co 16; g: choline chloride 12, Mg 0.8, Fe 6, Zn 5.6, $\mathrm{Mn} \mathrm{2.4,} \mathrm{Cu} 6.4 ;{ }^{2}$ native chicory inulin with an average degree of polimerization $\geq 10$

\section{Statistical analysis}

Data were analysed by one-way analysis of variance, followed by post hoc Tukey's HSD test using STATGRAPHICS ${ }^{\circledR}$ Centurion XVIver. 16.1.03 statistical package (StatPoint Technologies, Inc., Warrenton, VA, USA). The effects were considered to be significant at $P \leq 0.05$. 


\section{Results and discussion}

The most pronounced changes in analysed blood plasma parameters were observed in pigs fed $\mathrm{T} 2$ diet (Table 2). Plasma albumin concentration in those pigs was higher than in animals fed C diet. Feeding T2 diet significantly increased AST, ALT and ALP activity in comparison with animals fed T1 diet. Plasma GGT activity was significantly lower in the pigs fed T2 diet as compared with other groups. Significant increase in plasma iron concentration was observed in the animals fed T2 diet and slightly increased calcium level - in both treatment groups.

Both total protein and albumin concentrations in blood plasma are considered as markers of the liver functioning, reflecting partly its nutritional status (Kang, 2013). In the present study, unaffected total plasma protein and increased plasma albumin level in pigs fed both experimental diets may indicate physiological liver and gallbladder functions. The slight increase of serum albumin content after supplementation with chicory was noticed by Hassan

Table 2. Biochemical indices of blood plasma in pigs fed control diet (C) and diets supplemented with $2 \%$ of chicory inulin (T1) or $4 \%$ of dried chicory root (T2)

\begin{tabular}{|c|c|c|c|c|c|}
\hline \multirow{2}{*}{$\begin{array}{l}\text { Biochemical } \\
\text { parameter }\end{array}$} & \multicolumn{3}{|l|}{ Group } & \multirow{2}{*}{ SEM } & \multirow{2}{*}{$P$-value } \\
\hline & $\mathrm{C}$ & $\mathrm{T} 1$ & $\mathrm{~T} 2$ & & \\
\hline \multicolumn{6}{|l|}{ Content } \\
\hline total protein, $\mathrm{g} \cdot \mathrm{I}^{-1}$ & 62.2 & 63.7 & 66.0 & 0.74 & 0.092 \\
\hline albumin, $\mathrm{g} \cdot \mathrm{I}^{-1}$ & $33.9^{a}$ & $36.5^{\mathrm{ab}}$ & $38.4^{\mathrm{b}}$ & 0.62 & 0.005 \\
\hline urea, $\mathrm{mmol} \cdot \mathrm{I}^{-1}$ & 2.56 & 2.61 & 2.81 & 0.249 & 0.918 \\
\hline creatinine, $\left.\mu \mathrm{mol} \cdot\right|^{-1}$ & $\begin{array}{l}1 \quad 91.4 \\
\end{array}$ & 101.1 & 86.6 & 3.46 & 0.243 \\
\hline bilirubin, $\mu \mathrm{mol} \cdot \mathrm{I}^{-1}$ & 4.48 & 6.16 & 7.22 & 0.601 & 0.089 \\
\hline $\mathrm{TIBC}^{1}, \mu \mathrm{mol} \cdot \mathrm{I}^{-1}$ & 105 & 110 & 111 & 2.2 & 0.508 \\
\hline $\mathrm{Fe}, \mu \mathrm{mol} \cdot \mathrm{I}^{-1}$ & $15.6^{\mathrm{a}}$ & $19.8^{\mathrm{ab}}$ & $30.5^{b}$ & 2.29 & 0.010 \\
\hline $\mathrm{Ca}, \mathrm{mmol} \cdot \mathrm{I}^{-1}$ & 2.97 & 3.17 & 3.19 & 0.042 & 0.052 \\
\hline $\mathrm{P}, \mathrm{mmol} \cdot \mathrm{I}^{-1}$ & 2.60 & 2.97 & 2.84 & 0.077 & 0.102 \\
\hline $\mathrm{Mg}, \mathrm{mmol} \cdot \mathrm{I}^{-1}$ & 0.47 & 0.48 & 0.48 & 0.020 & 0.967 \\
\hline $\mathrm{Cl}, \mathrm{mmol} \cdot \mathrm{I}^{-1}$ & 97.1 & 99.8 & 96.1 & 0.84 & 0.197 \\
\hline \multicolumn{6}{|l|}{ Activity, $U \cdot I^{-1}$} \\
\hline $\mathrm{AST}^{2}$ & $33.9^{\mathrm{ab}}$ & $28.7^{\mathrm{a}}$ & $44.2^{b}$ & 2.37 & 0.017 \\
\hline $\mathrm{ALT}^{3}$ & $24.4^{\mathrm{a}}$ & $25.3^{\mathrm{a}}$ & $49.6^{b}$ & 2.84 & 0.001 \\
\hline $\mathrm{ALP}^{4}$ & $411^{a}$ & $450^{\mathrm{a}}$ & $794^{b}$ & 44.8 & 0.001 \\
\hline $\mathrm{GGT}^{5}$ & $29.4^{\mathrm{a}}$ & $31.6^{a}$ & $19.1^{b}$ & 1.93 & 0.011 \\
\hline $\mathrm{LDH}^{6}$ & 542 & 551 & 598 & 17.7 & 0.385 \\
\hline $\mathrm{CK}^{7}$ & 874 & 1052 & 1193 & 117.1 & 0.546 \\
\hline amylase & 1154 & 1161 & 1070 & 60.3 & 0.804 \\
\hline cholinesterase & 644 & 569 & 577 & 23.0 & 0.351 \\
\hline
\end{tabular}

${ }^{1}$ TIBC - total iron binding capacity; ${ }^{2}$ AST - aspartate aminotransferase, ${ }^{3} \mathrm{ALT}$ - alanine aminotransferase, ${ }^{4} \mathrm{ALP}$ - alkaline phosphatase, ${ }^{5}$ GGT - y-glutamyltransferase; ${ }^{6} \mathrm{LDH}$ - lactate dehydrogenase ${ }^{7} \mathrm{CK}$ - creatine kinase; ab - means with different superscripts within a row are significantly different (significant $P$-value written in bold) and Yousef (2010) in rats. Increased activity of AST, ALT and ALP was observed in animals fed diet supplemented with dried chicory root. This is in agreement with the data obtained by the Nasiri et al. (2014) in rats fed chicory in the amount of $1 \mathrm{~g} \cdot \mathrm{kg}^{-1}$ of body weight. On the other hand, Hassan and Yousef (2010) showed ameliorating effect of chicory inulin and chicory root against various chemical compounds, which was manifested by decreased activity of the liver enzymes in blood serum. The elevated levels of plasma ALP activity observed in the present study, are more likely due to increased bone formation than to the liver response. The above may be confirmed by the fact that we showed significantly lower plasma activity of GGT in pigs fed diet with chicory root addition. Kang (2013) suggested that increased ALP activity with the significant increase in GGT activity must originate from the liver rather than metabolic activity of bones. Additionally, in human adolescents predominant ALP serum activity derives from bone origin ALP fraction as the effect of intense skeletal growth (Van Hoof et al., 1990; Kang, 2013). Serum total ALP activity is proposed as a marker of bone formation and osteoblast activity in growing adolescent pigs (Tymczyna et al., 2012). It is also noteworthy that bones morphology and their metabolic processes in pigs are similar to those evidenced in humans (Smink et al., 2003). In these groups slight increase in blood plasma calcium concentration was observed. Effectiveness of dietary supplementation with fructans on intestinal calcium absorption and bone mineralization have been confirmed in young adolescents. Moreover, it has been evidenced that the most impressive effects are observed when mixture of fructans with both high and low DP are used (Abrams et al., 2005). The dose-depend relation between dietary ITF and bone mineralization was confirmed (Scholz-Ahrens et al., 2002). It was also demonstrated that polyphenols that are present in the chicory root have the ability to enhance osteogenesis (Chen et al., 2005). Most likely the observed increase in ALP activity in animals fed dried chicory root results from escalated bone mineralization process as an effect of wide spectrum of short- and long-chain ITF and polyphenolic compounds present in dried chicory root.

In the present study, increased level of plasma iron in pigs fed diet supplemented with dried chicory root was observed. In pigs fed diet containing $2 \%$ of inulin slight increase in iron concentration was also demonstrated. The effect of inulin supplementation on iron bioavailability in weanling pigs fed with maize-soyabean-based diet was showed by Yasuda et al. (2006). The authors observed dose- 
dependent relation between inulin level and blood haemoglobin concentration. The highest utilization of iron, intrinsically present in maize-soyabeanbased diet, was reported when $4 \%$ of inulin was implemented to the diet. It should be pointed out that the most pronounced changes were observed after at least 5 weeks of inulin ingestion. The authors also confirmed that feeding diet with $4 \%$ inulin addition increases soluble iron concentration in three segments (proximal, middle and distal) of the colon. Weaning piglets fed diet supplemented with $4 \%$ of inulin with different DP: $\mathrm{n}=10-60$ (Raftaline HP); $\mathrm{n}=2-7$ (Raftilose P95); 1:1 mixture of HP and P95 (Synergy1) had higher blood haemoglobin and haematocrit values in comparison to the animals fed control diet (Yasuda et al., 2009). Furthermore, pigs fed all mentioned types of inulin had increased ferritin expression in the liver and mucosa of caecum and colon on both transcript and protein level (Tako et al., 2008; Yasuda et al., 2009). Dietary inulin caused up-regulation of genes encoding iron transporters in colonocytes of weaned pigs. Surprisingly, the same effect was observed in the duodenum, suggesting that inulin itself, not only its fermentation products, may also affect gene expression in enterocytes (Tako et al., 2008). In the present study, increased iron concentration, observed in blood plasma of pigs fed chicory root, can be the effect of synergy between fructans and other biological substances present in chicory.

\section{Conclusions}

Dietary fructans and dried chicory root, as their source, do not affect liver functioning. Feeding diet supplemented with dried chicory root significantly improves plasma iron concentration in growing pigs. Additionally, dried chicory root may also increase calcium concentration in blood plasma which, in turn, may enhance bone mineralization and growth in young animals. Nevertheless, to confirm this hypothesis further studies are necessary.

\section{Acknowledgements}

This work was supported by grant from National Centre of Science, Poland, Project No. 2012/05/D/ NZ9/01604.

\section{References}

Abrams S.A., Griffin I.J., Hawthorne K.M., Liang L., Gunn S.K., Darlington G., Ellis K.J., 2005. A combination of prebiotic short- and long-chain inulin-type fructans enhances calcium absorption and bone mineralization in young adolescents. Am. J. Clin. Nutr. 82, 471-476
Chen C.-H., Ho M.-L., Chang J.-K., Hung S.-H., Wang G.-J., 2005. Green tea catechin enhances osteogenesis in a bone marrow mesenchymal stem cell line. Osteoporos. Int. 16, 2039-2045, https://doi.org/10.1007/s00198-005-1995-0

Cheng G., Hao H., Xie S., Wang X., Dai M., Huang L., Yuan Z., 2014. Antibiotic alternatives: the substitution of antibiotics in animal husbandry? Front. Microbiol. 5, 217, https://doi.org/10.3389/ fmicb.2014.00217

Gibson G.R., Roberfroid M.B., 1995. Dietary modulation of the human colonic microbiota: introducing the concept of prebiotics. J. Nutr. 125, 1401-1412

Hassan H.A., Yousef M.I., 2010. Ameliorating effect of chicory (Cichorium intybus L.)-supplemented diet against nitrosamine precursors-induced liver injury and oxidative stress in male rats. Food Chem. Toxicol. 48, 2163-2169, https://doi.org/10.1016/j. fct.2010.05.023

Kang K.-S., 2013. Abnormality on liver function test. Pediatr. Gastroenterol. Hepatol. Nutr. 16, 225-232, https://doi.org/10.5223/ pghn.2013.16.4.225

Lepczynski A., Herosimczyk A., Ozgo M., Skomial J., Taciak M., Barszcz M., Berezecka N., 2015. Dietary supplementation with dried chicory root triggers changes in the blood serum proteins engaged in the clotting process and the innate immune response in growing pigs. J. Physiol. Pharmacol. 66, 47-55

Lepczyński A., Herosimczyk A., Ożgo M., Marynowska M., Pawlikowska M., Barszcz M., Taciak M., Skomiał J., 2016. Dietary chicory root and chicory inulin trigger changes in energetic metabolism, stress prevention and cytoskeletal proteins in the liver of growing pigs - a proteomic study. J. Anim. Physiol. Anim. Nutr. [Epub ahead of print, 17.11.2016] https://doi. org/10.1111/jpn.12595

Nasiri A., Ziamajidi N., Behrouj H., Abbasalipourkabir R., Dehghan A., 2014. The effects of aqueous extract of chicory root on steatosis, lipid profile and liver damage enzyme markers in tamoxifen-treated rats. Mol. Biochem. Diag. 1, 185-194

Scholz-Ahrens K., Açil Y., Schrezenmeir J., 2002. Effect of oligofructose or dietary calcium on repeated calcium and phosphorus balances, bone mineralization and trabecular structure in ovariectomized rats. Br. J. Nutr. 88, 365-377, https://doi. org/10.1079/BJN2002661

Scholz-Ahrens K.E., Schrezenmeir J., 2007. Inulin and oligofructose and mineral metabolism: the evidence from animal trials. J. Nutr. 137, 2513S-2523S

Seifert S., Watzl B., 2007. Inulin and oligofructose: review of experimental data on immune modulation. J. Nutr. 137, 2563S-2567S

Smink J.J., Buchholz I.M., Hamers N., van Tilburg C.M., Christis C., Sakkers R.J.B., de Meer K., van Buul-Offers S.C., Koedam J.A., 2003. Short-term glucocorticoid treatment of piglets causes changes in growth plate morphology and angiogenesis. Osteoarthr. Cartil. 11, 864-871, https://doi. org/10.1016/S1063-4584(03)00187-0

Tako E., Glahn R.P., Welch R.M., Lei X., Yasuda K., Miller D.D., 2008. Dietary inulin affects the expression of intestinal enterocyte iron transporters, receptors and storage protein and alters the microbiota in the pig intestine. Br. J. Nutr. 99, 472-480, https:// doi.org/10.1017/S0007114507825128

Tymczyna B., Tatara M.R., Krupski W., Tymczyna-Sobotka M., Łuszczewska-Sierakowska I., Bachanek T., 2012. Relationships between biochemical bone metabolism indices and morphometric, densitometric and mechanical properties of mandible in 6-month-old pigs. Ann. Agric. Environ. Med. 19, 535-539 
Van Hoof V.O., Hoylaerts M.F., Geryl H., Van Mullem M., Lepoutre L.G., De Broe M.E., 1990. Age and sex distribution of alkaline phosphatase isoenzymes by agarose electrophoresis. Clin. Chem. 36, 875-878

Yasuda K., Dawson H.D., Wasmuth E.V., Roneker C.A., Chen C., Urban J.F., Welch R.M., Miller D.D., Lei X.G., 2009. Supplemental dietary inulin influences expression of iron and inflammation related genes in young pigs. J. Nutr. 139, 2018-2023, https://doi.org/10.3945/jn.109.110528
Yasuda K., Roneker K.R., Miller D.D., Welch R.M., Lei X.G., 2006. Supplemental dietary inulin affects the bioavailability of iron in corn and soybean meal to young pigs. J. Nutr. 136, 3033-3038 